\title{
En conSecuencia con la imagen. La imagen del cambio en una esquina de Tacubaya
}

\author{
Felipe Morales Leal
}

$\mathbf{L}$

a fotografía es uno de los productos creados por el hombre que no ha dejado de estar presente en casi cualquier rincón del mundo; millones de fotógrafos disparan a diario sus máquinas persiguiendo distintos objetivos, desde el retrato de familia hasta la imagen publicitaria.

Más allá de los usos de la fotografía, en lo particular, es de mi interés estudiar el valor que a ésta se le otorga en los trabajos de las distintas disciplinas sociales; objetivo que surge a partir del acercamiento constante con estos productos y del enriquecimiento académico que he adquirido en torno al tema en las últimas fechas.

Cuando se toma una foto ésta siempre adquiere un valor determinado por el contexto en el que se produce, el cual en muchos casos coincide, en este primer momento, con el uso que se le dará; es decir, regresando al retrato familiar o a la foto publicitaria, diremos que el primero contiene esa carga emotiva que incitó a un grupo familiar a enfrentarse al disparo de la máquina; su valor reside en el hecho de compartir el momento, es meramente afectivo. Por su parte, la foto publicitaria vale en razón del producto que busca dar a conocer. Este primer valor es aplicable a toda imagen y podemos decir que es el más concreto a lo largo de su historia.
Probablemente quienes producen una imagen llegan a pensar lo valiosa que ésta será en un futuro y la resguardan con mucho cuidado; no obstante, el valor que se le irá otorgando con el paso del tiempo siempre será una interrogante, porque depende de los intereses y motivaciones de aquellas personas que se acerquen a cuestionarla. Incluso los álbumes familiares pueden tener distintas lecturas y generar distintos puntos de vista. Con valor nos referimos a los significados que la imagen tiene para las personas, los cuales en definitiva se van transformando. Es desde este enfoque que abordamos el tema de la imagen.

Las imágenes, en general, y la fotografía, en particular, adquieren un valor específico para aquellos que, interesados en la investigación social, las utilizan como fuentes de información. La imagen es de gran utilidad cuando el objetivo que se persigue es explicar algunos detalles de lo cotidiano, sobre todo ante la falta de atención que otros documentos prestan a este tipo de aspectos; esta posible revaloración en muchos de los casos no es ni siquiera pensada por el autor de la imagen.

En este sentido, y retomando lo dicho respecto al valor, podemos inferir que éste necesariamente depende de los objetivos del nuevo usuario de la imagen. Ante una 
misma fotografía se pueden tener muy diversas actitudes; esto incluso entre colegas de una misma disciplina.

\section{El LUGAR EN EL CONTEXTO}

Tomando en consideración lo antes expuesto prosigue ejemplificar, con un caso concreto, la revaloración que una serie de imágenes, creadas por varios autores con diversos motivos, adquirió a partir del interés por estudiar la transformación urbana de un lugar en el barrio de Tacubaya; todo ello en el marco de una investigación más amplia. ${ }^{1}$

Uno de los principales intereses de este estudio fue entender cómo y por qué fue construido el edificio Ermita, ubicado en la intersección de las avenidas Jalisco y Revolución, en Tacubaya, ya que en el interior del mismo se alberga el cine Hipódromo Condesa, que era el objeto principal de mi investigación. Así fue como surgieron una serie de interrogantes, cuyas respuestas se quedaban cortas al cuestionar la mayoría de la bibliografía y de los escritos que sobre el tema existen. Por tal motivo recurrir a otro tipo de fuentes era indispensable. Una de estas fuentes de investigación fue la imagen.

Del trabajo en los distintos archivos se logró rescatar un corpus de imágenes del barrio de Tacubaya, a partir de las cuales se generaron preguntas que, en el marco del proceso de investigación documental, fueron produciendo una serie de explicaciones puestas a consideración en el estudio antes referido. Del total de las imágenes encontradas, en este artículo en particular hablaremos de una selección

\footnotetext{
${ }^{1}$ Morales, Triángulo, 2003.
}

agrupada a propósito de un lugar, la ya antes referida intersección de las actuales avenidas Jalisco y Revolución, sitio en el cual existía un viejo portal de estilo clásico que fue sustituido por el edificio Ermita hacia finales de la década de los veinte del siglo XX.

Cuando abordamos la historia de un lugar, nos encontramos con distintas interpretaciones; en esta ocasión el camino que trazamos busca explicar el porqué del cambio en el paisaje de la zona, dejando de lado las versiones románticas con toques de nostalgia, tentación que muchas investigaciones no han podido librar. Para entender la transformación del sitio mencionado necesariamente debemos recurrir al cambio urbano de Tacubaya desde mediados del siglo XIX hasta principios del xx. Para comenzar abordaremos un par de imágenes que en apariencia tienen poco en común: la primera de ellas es una litografía elaborada en el siglo $\mathrm{XIX}^{2}$ (véase p. 27) y la segunda una fotografía aérea tomada en 1936 por la Compañía Mexicana de Aerofoto (véase p. 29). Ambas son documentos que nos ayudan a evidenciar el cambio de Tacubaya. Entre ellas existe un considerable número de años, de ahí las notables diferencias entre lo que era una pequeña ciudad y una verdadera urbe en pleno crecimiento.

El tiempo transcurrido entre la realización de una y otra necesariamente fue

${ }^{2}$ Las litografías, si bien no son imágenes que capturen un instante, como sí lo hace la fotografía, nos sirven como fuente de investigación porque fueron creadas a partir de la visión de un artista que refleja las cosas como las percibió. No obstante, una imagen de este tipo adquiere mayor relevancia cuando el análisis del contexto de la época nos revela que lo que en ella se puede observar concuerda con la idea que otras fuentes nos generan al respecto. 
acompañado de cambios económicos, sociales y culturales. Para entender cómo Tacubaya llegó a ser lo que la imagen de 1936 nos presenta, es necesario hacer un recorrido histórico del lugar. El punto de partida es la litografía de la Tacubaya decimonónica (véase p. 27).

A principios del siglo XIX, la zona de Tacubaya estaba poblada por los naturales del lugar, los primeros cimientos de lo que posteriormente sería llamada ciudad de Tacubaya fueron puestos durante la década de 1850. Cabe aclarar que la ciudad de Tacubaya era la principal población del municipio que llevaba el mismo nombre, el cual formaba parte del Distrito Federal, según lo dispuesto en la Constitución de $1824 .^{3}$

El municipio estaba ubicado al poniente de la ciudad de México, donde se concentraba el poder económico y político de nuestro país. La vida diaria de la gente adinerada se desarrollaba en la parte que corresponde al actual centro histórico; ahí era donde el trabajo, los negocios, la cultura, la política y la religión tenían sus principales sedes. Sin embargo, el descanso demandaba un lugar que permitiera alejarse de las rutinas; uno de esos lugares fue la ciudad Tacubaya.

Las condiciones orográficas al poniente de la ciudad de México eran atractivas para las elites de la capital. En Tacubaya los bosques, los ríos y la temperatura templada eran un verdadero incentivo. Sin lugar a dudas, ésta fue una de las razones por las cuales se comenzaron a construir las mansiones que darían origen a la ciu-

${ }^{3}$ En lo subsecuente, cada vez que hablemos de Tacubaya nos estaremos refiriendo a la ciudad, salvo en el caso que aclaremos que hacemos mención al municipio. dad, ubicada en la cabecera del municipio. La gente adinerada decidió instalar ahí sus casas de campo.

Como se puede apreciar en la litografía del siglo XIX realizada desde una azotea, las casas que existían en el lugar eran de gran tamaño, los nuevos dueños se apropiaron de terrenos inmensos donde caballerizas, jardines, fuentes y graneros eran algo común (véase p. 27). Pocos rastros quedan en esa imagen de lo que pudieron haber sido los pobladores originales; éstos fueron desplazados hacia las orillas.

La vialidad que se observa en la imagen fue durante muchos años, incluso hasta bien entrado el siglo Xx, la más importante de Tacubaya; era el acceso al centro de la ciudad. Esta avenida cambió varias veces de nombre, en un tiempo se llamó calle Imperial, después calle Real, más tarde avenida Juárez y por último obtuvo el nombre que a la fecha conserva: avenida Jalisco.

$\mathrm{Si}$ apreciamos bien la imagen podemos ver la representación de los aristócratas, finamente vestidos, platicando, caminando por las calles o paseando en sus carruajes; en cambio, a la gente humilde se la ve trabajando, cargando leña, arreando el rebaño y prestando demás servicios. En los tiempos en que se creó esta imagen, las diferencias sociales eran muy marcadas.

Las grandes mansiones cubrieron el panorama durante décadas y eran tan lujosas que Manuel Payno las llamó "verdaderas villas italianas". ${ }^{4}$ Familias como los Escandón, los Jemison, los Algara y los Mier edificaron grandes palacios, sobre todo a orillas de las avenidas principales. Algunas de estas casas llamaban tanto la

${ }^{4}$ Castro, Méxica, 1857 , p. 76. 
atención por su suntuosidad que fueron fotografiadas para $E l$ Mundo llustrado, publicación de principios del siglo $\mathrm{XX}$ (véase p. 42).

Para llegar a Tacubaya desde la ciudad de México necesariamente se tenía que tener o alquilar un carruaje; la distancia de más de siete kilómetros podía bien recorrerse en menos de una hora. De cualquier forma este viaje era poco común pata la mayoría de la población. Con el paso de los años la situación política y económica del país se modifica, los transportes se transforman y necesariamente la ciudad de Tacubaya comienza a ser diferente. Durante las últimas décadas del siglo XIX llega una importante cantidad de gente; con la puesta en marcha de las líneas del tranvía, el viaje a la ciudad de México se hace más corto y barato, esto facilita la migración de otros sectores de la población.

Hacia finales de siglo, el interés por establecerse en el lugar creció; las mansiones dejaron de construirse y la vivienda se fue haciendo más austera porque los nuevos pobladores no tenían el poder económico de las viejas elites. Pronto la que era una ciudad lujosa y exclusiva adquirió un carácter popular.

Una fotografía del centro de Tacubaya nos permite apreciar el Portal de Cartagena (véase p. 57), el mismo que se veía al centro de la primera imagen aquí revisada. En el interior de esos arcos se desarrollaba una importante actividad comercial; desde aquellos años, Tacubaya se convirtió en el punto convergente de los habitantes del poniente del Distrito Federal, por lo que los puestos en la calle eran algo común; en definitiva, éste era el punto nodal, más si tomamos en cuenta que enfrente se ubicaba el mercado principal.
En esta imagen ya no se aprecian los aristócratas de años atrás, por el contrario se ve a la clase popular, que ya para finales de siglo se había apoderado de gran parte de la ciudad; una importante cantidad de personas llegó a vivir al lugar hacia principios del siglo xx. En el año de 1900 había un total de $18342^{5}$ habitantes en todo el municipio, la mayoría de los cuales se instaló en los alrededores del centro de Tacubaya. Otro aspecto a destacar es el desarrollo del transporte: en la imagen se aprecia un tranvía de mulitas pasando junto al portal; la línea de tranvías corría hasta el Zócalo de la ciudad de México.

En este año, 1900, se da otro cambio que afecta de forma directa al crecimiento de Tacubaya; en enero se inaugura el primer tranvía eléctrico del país, cuya primer ruta corría a Tacubaya. Con el nuevo sistema de tracción, el recorrido a la ciudad de México se hacía en mucho menor tiempo; lo que antes implicaba más de media hora con el tranvía de mulitas, se simplificó a menos de quince minutos con la electricidad.

Es muy probable que a partir de ese momento se incrementara el número de personas que decidieron vivir en Tacubaya, ya que con el tranvía tenían la posibilidad de seguir trabajando en la ciudad de México. No es casual que a finales del siglo XIX, los terrenos se hayan comenzado a fraccionar, con lo que surgieron nuevas colonias como Escandón, San Miguel Chapultepec y San Pedro de los Pinos.

En diez años Tacubaya creció en una forma nunca antes vista. La población del municipio se duplicó llegando a 37553 habitantes en el año de $1910 ;{ }^{6}$ el tipo de

\footnotetext{
${ }^{5}$ Censo, 1901.

${ }^{6}$ Censo, 1911.
} 
vivienda cambió, las mansiones fueron sustituidas por casas más modestas y en muchos casos por vecindades. El ritmo vertiginoso de crecimiento no paró ahí; nueve años después, en 1919, la población total sumaba $51312^{7}$ habitantes y para 1921 la cifra aumentó hasta $54775 .^{8}$

Para entender de forma más clara el crecimiento de Tacubaya basta con comparar dos planos de la ciudad, uno elaborado hacia finales del siglo XIX (véase p. 89) y otro en las primeras décadas del XX (véase p. 95). En el plano de 1883 podemos apreciar el predominio de los grandes terrenos; Tacubaya era una ciudad pequeña que se concentraba en las cercanías del Portal de Cartagena. En cambio, en el plano de 1932 ya se aprecia el trazo de las nuevas colonias. La expansión se dio hacia el norte con la colonia San Miguel Chapultepec, al sur con San Pedro de los Pinos y al este con la colonia Escandón.

Ahora bien, para sustentar en forma más sólida todo lo expuesto, es pertinente aterrizar nuestro estudio en alguna zona de la ciudad. El sitio elegido es uno que por su historia ha sido y sigue siendo de los más representativos de Tacubaya: se trata de la ya mencionada intersección de las avenidas Jalisco y Revolución. Este lugar destaca por ser el punto principal por donde arribaron y siguen arribando aquellos que acuden a Tacubaya.

Como se pudo ver en el plano anterior, la unión de las dos avenidas forma uno de los vértices de un terreno de forma triangular, en cuyo interior se han edificado dos de las construcciones más repre-

\footnotetext{
${ }^{7}$ Municipalidad de Tacubaya, 1919, en Archivo Histórico del Distrito Federal, Ayuntamiento, inv. 21, $\exp 107$.

${ }^{8}$ Censo, 1930.
}

sentativas de Tacubaya, al grado de haber testificado el constante tránsito de personas por sus aceras durante ya más de un siglo. Abordar las transformaciones de dicho lugar nos permite evidenciar el cambio urbano que se dio en Tacubaya en las primeras décadas del siglo Xx.

\section{De PORTAL A EDIFICIO}

En la segunda mitad del siglo XIX llegó a Tacubaya la familia Mier, cuya cabeza era el señor Antonio Mier y Celis, que entre otras cosas fue el primer presidente de la Junta de Gobierno del Banco de México. Los Mier, como muchas otras familias de adinerados, se interesaron por los terrenos de la ciudad y adquirieron una finca de importantes dimensiones cuya delimitación estaba marcada por las actuales avenidas Jalisco y Revolución, y por la calle Martí; justo el triángulo al que nos venimos refiriendo.

En el terreno de los Mier se edificaron distintas construcciones; entre ellas una casa habitación (con todo lo que en esos momentos necesitaba una residencia de la elite), una capilla y edificios de asistencia privada. Pero, sin lugar a dudas, el inmueble más conocido por la población en general era el portal ubicado en el vértice norte del triángulo, en la intersección ya mencionada.

Uno de los principales caminos para llegar a Tacubaya desde Chapultepec era el que pasaba justo frente a la hacienda de la Condesa; en la imagen publicada por Casimiro Castro se aprecia un carruaje que a trote veloz se dirige a Tacubaya, la cual se alcanza a ver en la parte superior derecha de la litografía (véase p. 101). Quienes llegaban a la ciudad por este ca- 
mino se encontraban de frente con el portal de la familia Mier.

El portal era una construcción de estilo clásico que se levantaba a más de catorce metros sobre el nivel de la calle. La edificación era engalanada por cuatro columnas que se anteponían en la fachada, dos balcones, dos puertas de más de tres metros y una impresionante reja principal de aproximadamente seis metros de alto. La herrería y los acabados de la fachada destacaban por su particular detallado, el cual tiene su máxima expresión al centro del portal y de la reja principal, donde resalta el nombre de la familia Mier con una tipografía muy particular. El portal era característico de Tacubaya, al grado de ser la única construcción representada en el primer croquis de la ciudad, la fachada se alcanza a apreciar en la esquina inferior derecha (véase p. 89).

El portal fue fotografiado hacia finales del siglo XIX, su estructura sobresalía entre todas las construcciones de la zona; ya para estas fechas, una reja de más de dos metros, que originalmente no existía, cubría toda la fachada. Otro de los detalles que se alcanza a distinguir es la poca profundidad de la construcción, ya que era sólo una puerta de entrada y en realidad ocupaba una parte ínfima del terreno triangular que ya antes presentamos; detrás del portal destacan algunos árboles de gran tamaño que formaban parte del área boscosa en el interior del predio (véase p. 106).

Justo lo que se ve en la imagen era lo que se encontraba la gente cuando llegaba a la ciudad. La avenida que se aprecia es la que durante muchos años llevó el nombre de avenida Juárez, que como ya se dijo era el acceso principal al centro de Tacubaya. Los rieles que se pueden ver eran del tranvía de mulitas que corría hacia el Zócalo de la ciudad de México.

La calle de Calvario era la vialidad que se ubicaba al otro lado del portal, una litografía de principios del siglo $\mathrm{xx}$ nos permite apreciarla (véase p. 109). Una vez más el encuadre es frontal, la estructura del portal es prácticamente idéntica a la vista en la imagen anterior; el único cambio considerable es la desaparición de la fuente que se encontraba en las afueras, frente a la reja principal. En esta segunda imagen se aprecia con mayor detalle la profundidad del portal que, como se verá adelante, no es de gran tamaño.

Tomando como punto de partida las dos imágenes anteriores podemos llegar a la conclusión de que ésta era una zona que comenzaba a desarrollar una importante actividad comercial. En la fotografía de la avenida Juárez ya se advierte la presencia de algún establecimiento mercantil, cosa que sería común años más tarde.

Durante las dos primeras décadas del siglo Xx Tacubaya creció de forma constante, lo cual se nota en algunas de las fotografías tomadas durante esos años (véase p. 117). En la imagen se aprecia la intersección de las avenidas Juárez y Morelos; ésta última ya había dejado atrás el nombre de calle de Calvario.

Justo frente al portal de la familia Mier se advierte la presencia de dos tranvías eléctricos; en las inmediaciones se ubicaba la parada del transporte llamada Ermita, nombre puesto en alusión a una vieja capilla que se ubicaba en una glorieta cercana al portal; ésta era una de las paradas más importantes de Tacubaya. En la fotografía se aprecia a un grupo de personas acercándose al tranvía que viene sobre avenida Juárez y cuyo destino es la ciudad de México. 
El crecimiento de la población y las transformaciones sociales trajeron como consecuencia la instalación de más locales comerciales, la mayoría de ellos abiertos sobre la avenida Juárez, que desembocaba directamente al mercado que se encontraba frente al Portal de Cartagena. De cualquier forma, en la zona del Portal de los Mier también se abrieron nuevos negocios que, sumados a la presencia de la parada del transporte, produjeron una mayor circulación de personas por el área.

El tranvía eléctrico vino a cambiar la relación existente entre la ciudad de México y Tacubaya, la cantidad de personas que iban y venían de un lugar a otro creció en forma considerable; un claro ejemplo de lo anterior es el tranvía de dos pisos con remolque que corría hacia el Zócalo; como se puede ver, el transporte iba repleto de personas. Al fondo se aprecia la parte superior del portal de la finca de la familia Mier (véase p. 126).

No sólo el tranvía hacía base en el lugar; a la izquierda del portal, en la esquina de Morelos y Primavera, se ubicaba la base de los carros que también iban al Zócalo. Una fotografía de dicha intersección permite apreciar uno de esos autos, que existieron en las primeras décadas del siglo XX, en plena marcha rumbo a la avenida principal, misma que salía hacia Chapultepec; el vehículo lleva en el parabrisas un letrero que dice "Zócalo" (véase p. 135). Una vez más es de destacar el importante número de personas que circulan por la zona; se distinguen algunos comercios establecidos sobre la calle de Morelos $\mathrm{y}$ varios puestos ambulantes instalados en la glorieta de la calle Primavera.

La actividad comercial se aprecia con mayor detalle en la foto del Obrador de la Ermita (véase p. 173). Sobresale por su tamaño el local de la Empacadora Obrador de la Ermita; otros negocios de la zona eran una tienda de mayoreo, la peluquería El Lujo, un café, la refaccionaria Ford y la peluquería El Arte, además de tres establecimientos más, cuyo nombre no se distingue.

En la imagen también se nota de forma más clara uno de los puestos ambulantes que se instalaban en la zona, por cuya estructura se puede suponer que vendían alimentos o bebidas, ya que en el mostrador, debajo del techo de dos aguas, se alcanzan a distinguir algunos envases perfectamente alineados. Frente a este puesto también se ve una tienda de abarrotes en una estructura con forma de kiosco. En esta fotografía se aprecia con mayor detalle la base de los carros que salían hacia el Zócalo. Un último punto a destacar es la presencia de algunos anuncios espectaculares en las azoteas de los comercios, seguramente instalados en este lugar por la cantidad de gente que potencialmente podía mirarlos.

Una imagen más del portal nos permite resaltar un nuevo detalle que hay que tomar en cuenta para lo que será el futuro de la zona; se trata de los carteles publicitarios que se distinguen en la siguiente imagen, frente a la reja de los Mier (véase p. 185). Esas estructuras que se ven tapizadas de anuncios eran llamadas "caballos", muchas de ellas eran de madera y tenían una forma triangular que les permitía sostenerse en cualquier parte. Respecto a la presencia de estos objetos publicitarios cabe hacer un par de precisiones; la primera de ellas para resaltar que las estructuras están recargadas en la reja del portal, de lo cual deducimos el poco uso práctico que éste tenía; es decir, nadie entraba y salía de forma constante 
por estas puertas, de lo contrario no se hubiera permitido la instalación de esos anuncios en el lugar. La segunda de las acotaciones es en cuanto a los carteles ahí pegados. Como ya se ha mencionado, para la segunda década del siglo $\mathrm{xx}$, fecha aproximada de la toma, Tacubaya ya era una ciudad bastante poblada, de ahí que necesariamente se hayan desarrollado no sólo los servicios sino también las diversiones. Seguramente aquellos papeles estaban anunciando alguna de las funciones que se daban en el teatro Primavera, ubicado a una cuadra del portal sobre la calle Primavera, o una función de cine programada en ese mismo lugar o en alguno de los cuatro cines restantes que hubo en el municipio.

Por aquellos años el cine destacó como una de las diversiones preferidas entre los habitantes de la zona. En Tacubaya funcionaban el cine Cartagena, el Tacubaya, el Hollywood, el Barragán y el ya mencionado teatro Primavera.

La suma de factores como ubicación, transporte, comercio y publicidad nos dan pie para considerar que este sitio era un referente urbano, un lugar que desde la edificación del portal y hasta ese momento se reconocía como un punto de constante actividad con plena identificación por parte de todo aquel que llegaba a Tacubaya.

En la fotografía de Manuel Ramos podemos apreciar de forma detallada el portal; esta imagen fue tomada aproximadamente en 1925 (véase imagen de portada). Una vez más existe una cartelera recargada en la reja principal; en este caso, en concreto, se trata de un anuncio del cine Cartagena, que se encontraba en la calle de la Independencia, hoy calle Martí, justo donde terminaba el terreno de la fa- milia Mier hacia el sur. El Cartagena fue durante muchos años el cine más importante de Tacubaya.

La posición de la cartelera frente a la reja pone de manifiesto una vez más que el portal seguía sin tener un gran uso. Algo estaba sucediendo en el interior de la casa de los Mier.

En realidad, los cambios en la familia Mier habían comenzado décadas atrás, el señor Antonio Mier y Celis había fallecido en Europa a finales del siglo XIX y había dejado todas sus propiedades a su viuda, la señora Isabel Pesado de Mier; una de esas propiedades era la finca de Tacubaya, la cual no era ocupada por la heredera. La señora Isabel vivió por muchos años en Europa hasta que en el año de 1913 falleció y dejó todos sus bienes para la realización de obras de beneficencia." De esta forma se crea la fundación Mier y Pesado, institución de asistencia privada que a partir de ese momento controló el destino de los bienes de la familia Mier.

La nueva fundación heredó un importante capital que la consolidó como la institución de asistencia privada más poderosa del país; bajo estas circunstancias decidieron emprender nuevos proyectos con el afán de seguir capitalizándose. Una de esas propiedades heredadas por la fundación era la vieja finca de Tacubaya. En un plano elaborado por el catastro municipal se aprecia el trazo del terreno. Como se puede ver, el portal ocupaba una parte muy pequeña, justo en la intersección de las dos avenidas; lo que había detrás de él era una zona boscosa que prácticamente cubría más de $70 \%$ del área en cuestión (véase p. 199). La vegetación sólo era interrumpida por la casa habitación (ubi-

\footnotetext{
${ }^{9}$ Fernández, Tacubaya, 1991, p. 435.
} 
cada en la esquina de Juárez e Independencia), por la capilla y por el edificio que estaban hacia el centro del terreno.

- El terreno, con las características antes descritas, resultaba poco atractivo para la fundación Mier y Pesado, cuyo objetivo era obtener una importante suma de dinero. Lo poco que estaba construido no tenía gran utilidad económica. Fue ese interés por capitalizarse el que motivó a la institución a realizar un nuevo proyecto en Tacubaya, el cual fue encargado al arquitecto Juan Segura, quien lo presentó para su consideración hacia finales de la década de los veinte.

En 1929 el panorama de la intersección de las venidas Juárez y Morelos comenzaba a cambiar, el viejo portal de la familia Mier estaba siendo demolido; en la imagen se alcanzan a ver algunos trabajadores que a martillazos derriban la construcción (véase p. 220). Tiempo atrás se habían quitado los enrejados. El nuevo proyecto contemplaba la construcción de un edificio en esa punta del terreno, de tal forma que el portal ya no tenía ninguna utilidad.

Aquel mismo año cambia el régimen municipal y Tacubaya deja de ser un municipio del Distrito Federal; se la había integrado al Departamento Central y las viejas avenidas Juárez y Morelos cambiaron sus nombres a los que actualmente llevan: avenida Jalisco y avenida Revolución, respectivamente. ${ }^{10}$

Lo que iba a suceder en el amplio terreno de forma triangular es un ejemplo de cómo se estaba transformando Tacubaya; en el nuevo proyecto, la fundación Mier y Pesado contempló la construcción de un par de edificios, uno en la parte

${ }^{10}$ Folleto, 1931. norte de la vieja finca, cuyo objetivo principal era la obtención de rentas por concepto de vivienda, y otro en la parte sur, justo en la intersección de las dos avenidas.

La fotografía aérea es de gran utilidad para apreciar el resultado del nuevo proyecto (véase p. 221), la construcción que se levanta al sur del terreno, detrás de la zona boscosa, es el edificio Isabel, en cuyo interior había un importante número de departamentos listos para rentarse. La construcción de la parte norte fue bautizada con el nombre de edificio Ermita, edificado justo en la parte que ocupaba el portal de la familia Mier.

Esta imagen también nos sirve para ver el cambio en el tipo de construcción de los alrededores; ya no se edificaban mansiones de gran tamaño, lo que se aprecia es la proliferación de vecindades, sobre todo hacia el poniente de la avenida Revolución. Las condiciones económicas, sociales y administrativas eran otras, Tacubaya se había vuelto barrio.

El edificio Ermita lucía imponente desde la esquina de Revolución y Primavera, justo donde estaba la Empacadora Obrador de la Ermita, este encuadre, tomado de norte a sur, da pie para hablar de las características de la obra del arquitecto Juan Segura (véase p. 223). El edificio Ermita fue una obra revolucionaria que buscó atender las demandas de vivienda, comercio y entretenimiento que se tenían en la zona. En su interior se construyeron 78 departamentos de distintos tamaños, 19 locales comerciales y una sala de cine con tres niveles de butacas. Por un lado, tenemos a la fundación Mier y Pesado que desea capitalizarse y, por otro, un lugar que demanda ciertos servicios, por lo que queda claro que fue- 


\section{SECUENCIA}

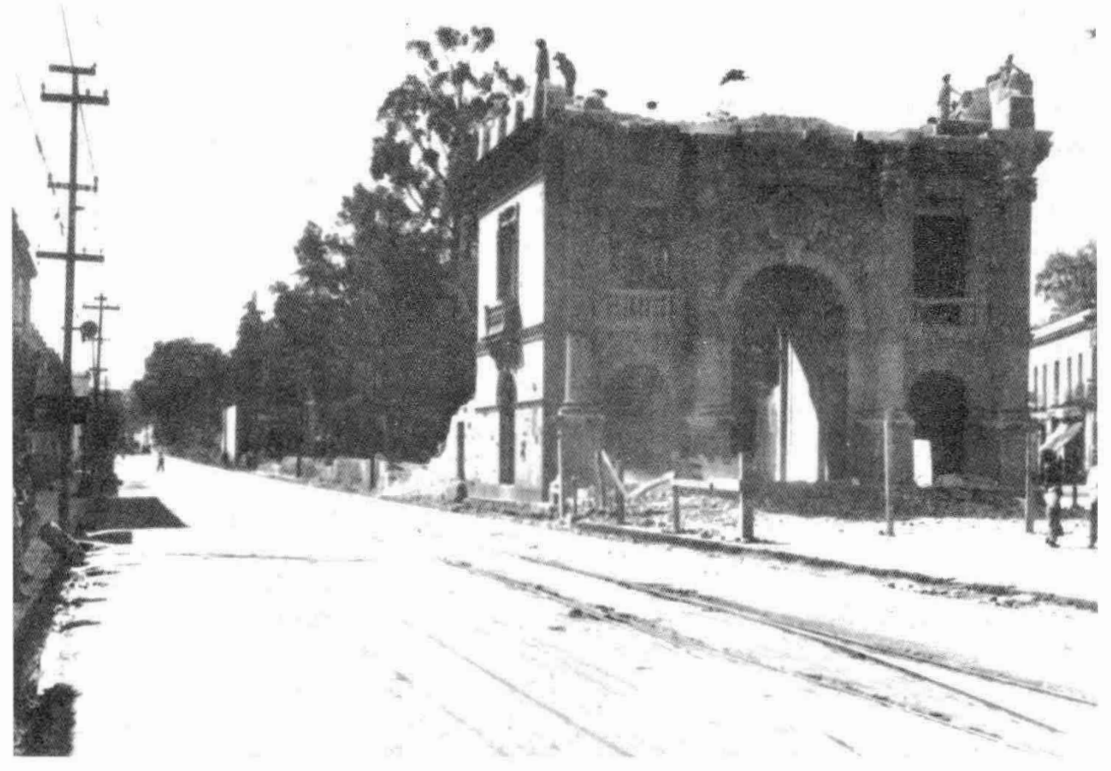




\section{SECUENCIA}

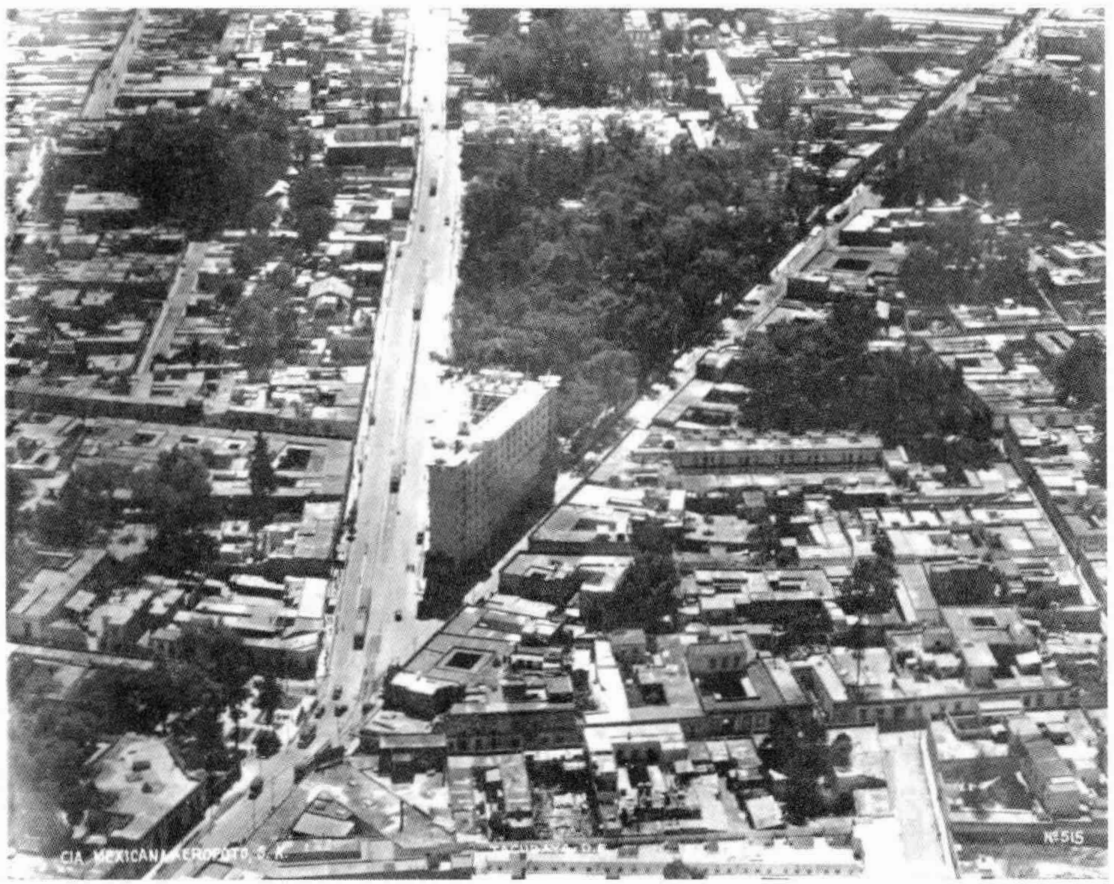


ron las condiciones del momento las que propiciaron el proyecto.

Mucha gente seguía llegando a Tacubaya, de ahí que la idea de hacer un edificio de departamentos fuera rentable; pero el edificio Ermita no quedó limitado a eso. El arquitecto, al considerar la actividad comercial que, como vimos, se daba en la zona, también proyectó la apertura de locales comerciales en las aceras de las dos avenidas principales. Para concluir su obra, al tener en cuenta la afición que ya los viejos cines de Tacubaya habían creado, incluyó la apertura de una sala de cine-teatro sobre la nueva calle que abrió en el terreno.

En la imagen del edificio se pueden apreciar los locales comerciales de la avenida Revolución que iban a ser rentados a distintos comerciantes; también se puede ver la sucursal del Banco de México, que ocupó por muchos años el local principal del edificio, cuya fachada tiene la misma orientación que tenía el portal de los Mier. Otro detalle a destacar son las ventanas de los distintos departamentos a los que se accede por cualquiera de las dos entradas ubicadas sobre las avenidas principales, justo donde se encuentra el arco de mayor tamaño.

Al fondo del edificio, donde no hay ventanas, se aprecia la estructura de la sala de cine, desde el primero y hasta el cuarto piso se observa lo que por dentro era un recinto de más de 2000 butacas. El único detalle que se nota desde este ángulo es la salida de emergencia hacia avenida Revolución, en forma de estructura abultada que se ve en la esquina inferior del inmueble. La entrada a lo que sería el cine Hipódromo Condesa fue ubicada en la parte posterior del edificio.
El edificio Ermita fue concluido en su totalidad hacia mediados de la década de los treinta y, sin lugar a dudas, representó un cambio trascendente en el panorama de Tacubaya. Se puede decir que con él se inaugura una nueva etapa en la historia de la arquitectura de la zona. Atrás quedó la arquitectura clásica para dar paso a la utilización del concreto y del acero.

Es así como la imagen nos ha posibilitado la obtención de datos que, en concordancia con otras fuentes de investigación, nos permiten llegar a conclusiones sobre el cambio urbano en esta zona de la ciudad.

A partir de aquella década de los treinta, la llegada a Tacubaya ya no se relacionaba con el viejo portal, pues en aquel lugar ya no existía el que por años fue el símbolo de la familia Mier; ahora, por el contrario, la gente se encuentra con un edificio en forma de rebanada de pastel que de igual forma llama la atención. La intersección de las avenidas Jalisco y Revolución sigue siendo un referente urbano y el edificio Ermita es, al igual que lo fue el portal en su tiempo, un inmueble representativo del barrio de Tacubaya.

\section{ARCHIVOS}

$\begin{array}{ll}\text { AGN } & \begin{array}{l}\text { Archivo General de la Nación. } \\ \text { AHDF }\end{array} \\ \text { Archivo Histórico del Distrito } \\ \text { CNMH } & \begin{array}{l}\text { Federal. } \\ \text { Fototeca de la Coordinación Na- } \\ \text { cional de Monumentos Históri- } \\ \text { cos-lNAH. }\end{array} \\ \text { Compañía Mexicana de Aerofoto. } \\ \text { CONACUITA Consejo Nacional para la Cultura } \\ \text { y las Artes. }\end{array}$

Fototeca Nacional. 


\section{SECUENCIA}

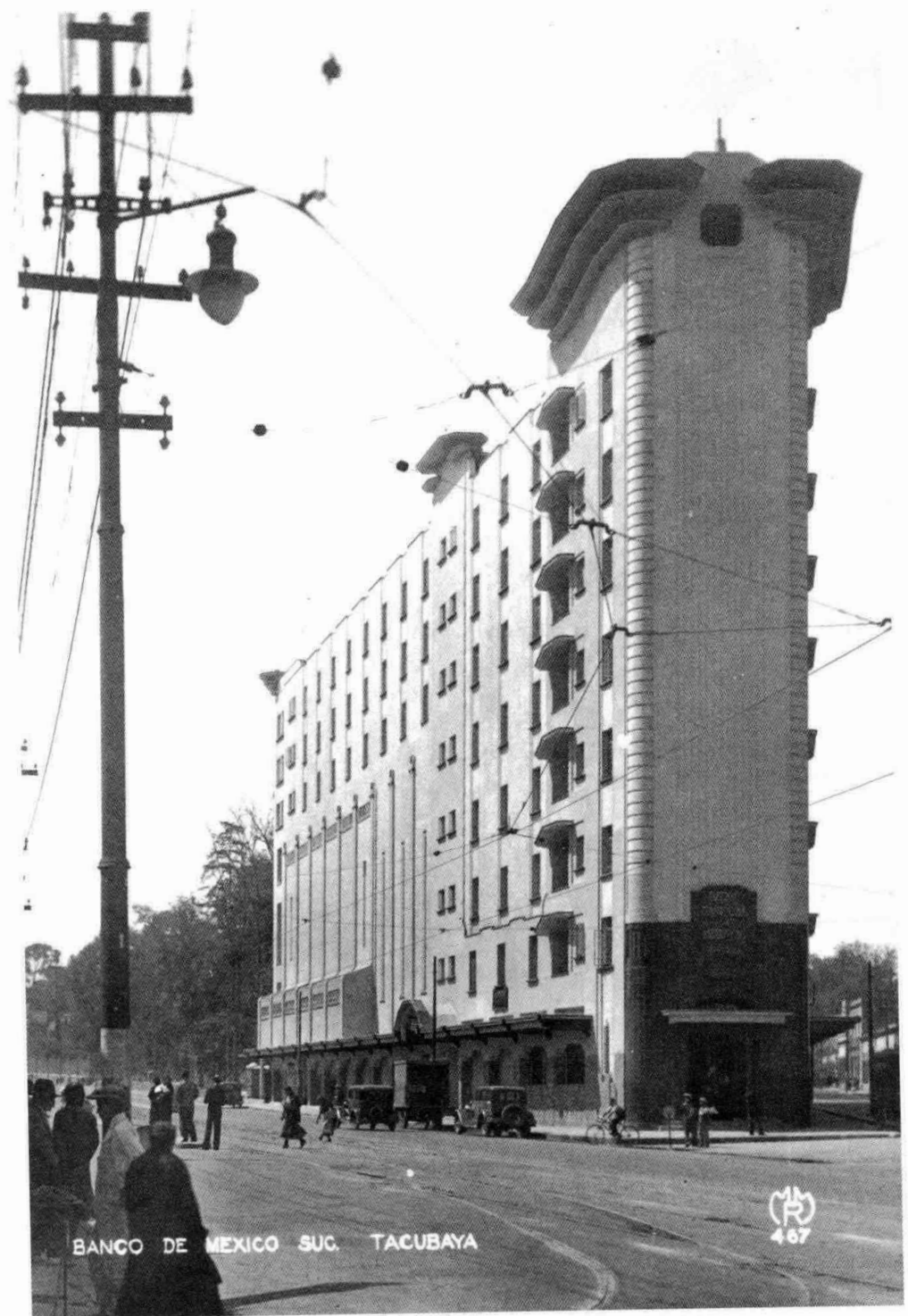


INAH Instituto Nacional de Antropología e Historia.

SINAFO Fototeca Nacional-INAH. Sistema Nacional de Fototecas.

\section{BIBLIOGRAFÍA}

- Apuntes para la historia y crítica de la arquitectura mexicana del siglo xx, 1900-1980", Cuadernos de Arquitectura y Conservación del Patrimonio Histórico, INBA/SEP, vol. II, núms. 22-23, 1982, México.

-Bache Cortés, Yolanda, "Con viajeros, residentes y cronistas: un paseo por Tacubaya en el siglo XIx" en Celia Maldonado y Carmen Reyna (coords.), Tacubaya, pasado y presente II, Yeuetlatolli, México, 1998.

-Castro, Casimiro, México y sus alrededores, Decaen Editor, México, 1857.

- Censo de población de la república mexicana, Dirección General de Estadística-Secretaría de la Economía Nacional, México, 1930.

-Censo general del D. F de 1910, México, Consejo Superior de Gobierno del D. F., juliodiciembre de 1911, t. xviI.

-Censo y división territorial del D. F. 1900 , Oficina Tip. de la Secretaría de Fomento, México, 1901.
-Fernández del Castillo, Antonio, Tacubaya, bistoria, leyenda y personajes, Porrúa, México, 1991.

-Folleto de nomenclatura de las calles, plazas y jardines del Departamento Central, comprendiendo las antiguas municipalidades de México, Tacuba, Tacubaya y Mixcoac, México, Dirección de Catastro-Departamento del Distrito Federal, 1931.

-García Salgado, 'Tomás, Análisis celular edificio Ermita, Facultad de Arquitectura-UNAM, México, 1984.

- Lombardo de Ruiz, Sonia, Atlas bistórico de la ciudad de México, Smurfit Cartón y Papel, CoNACULTA, México, 1997, 2 vols.

-Miranda Pacheco, Sergio, "Tacubaya: de suburbio veraniego a espacio conurbado. Imágenes de un proceso histórico" en Celia Maldonado y Carmen Reyna (coords.), Tacubaya, pasado y presente Il, Yeuetlatolli, México, 1998.

-Morales Leal, Felipe, "El triángulo de Tacubaya. La transformación de las salas cinematográficas, el caso del cine Hipódromo Condesa", tesis de licenciatura en Ciencias de la Comunicación, México, FCPyS-UNAM, 2003.

-Puig Casauranc, José Manuel, Atlas general del Distrito Federal, Condumex, México, 1929.

-Reyes, Aurelio de los, Cine y sociedad en México, 1896-1930, México, UNAM, 1993, vol. 2.

\section{IMÁGENES REFERIDAS}

Portada: Manuel Ramos, sin título, Tacubaya, ca. 1925, CNMH/CONACulTA-INAH/765-96.

p. 27, Casimiro Castro, La villa de Tacubaya [sur-norte], Tacubaya, 1855 en Casimiro Castro, México y sus alrededores, Decaen Editor, México, 1857.

p. 29, Compañía Mexicana de Aerofoto, México D. F, ciudad de México, 1936, Cumpañía Mexicana de Aerofoto, L 14-194.

p. 42, autor no conocido, Alrededores de México, Tacubaya, Tacubaya, 1900, publicado en El Mundo Ilustrado, México, 1900, t. 1. 
p. 57, autor no conocido, sin título, Tacubaya, ca., 1890, ConACULTA/INAH/SINAFo/Fototeca Nacional, núm. de inventario: 456441. Reproducción autorizada.

p. 89, García Sabas, Primer croquis de la ciudad de Tacubaya de los Mártires en 1883, Tacubaya, 1883 en Sonia Lombardo, Atlas bistórico de la ciudad de México, Smurfit Cartón y Papel/ConaCulta, México, 1997, vol. II, p. 267.

p. 95, autor no conocido, Plano de la ciudad de Tacubaya 1913-1932, Tacubaya, 1932, CNMH/CONACULTA-INAH/s. n.

p. 101, Casimiro Castro, La villa de Tacubaya [norte-sur, segunda versión], Tacubaya, 1865, publicado en Casimiro Castro, México y sus alrededores, Decaen Editor, México, 1857.

p. 106, autor no conocido, Calle Real, Tacubaya, ca. 1900, publicado en Liliana Gómez y Miguel Ángel de Quevedo, "Testimonios vivos, 20 arquitectos”, Cuadernos de Arquitectura y Conservación del Patrimonio Histórico, INBA/sEP, núms. 15-16, 1981, México.

p. 109, autor no conocido, Calle de Calvario, Tacubaya, ca. 1900, publicado en Tomás García Salgado, Análisis celular del edicifio Ermita, Facultad de Arquitectura-UNAM, México, 1984.

p. 117, autor no conocido, sin título, Tacubaya, ca. 1915, colección particular.

p. 126, autor no conocido, Tranvía frente al portal de los Mier, Tacubaya, ca. 1925, ConaculTA/INAH/SINAFO/Fototeca Nacional, núm. de inventario: 427082. Reproducción autorizada.

p. 135, autor no conocido, sin título, Tacubaya, ca. 1925, en Aurelio de los Reyes, Cine y sociedad en México, 1896-1930, México, UNAM, 1993, vol. 2, p. 206.

p. 177, autor no conocido, Obrador de la Ermita, Tacubaya, ca. 1925, CONACULTA/INAH/SINAFO/ Fototeca Nacional, núm. de inventario: 90417. Reproducción autorizada.

p. 189, autor no conocido, La ermita, Tacubaya, Tacubaya, ca. 1925, ConACulTA/INAH/SINAFO/ Fototeca Nacional, núm. de inventario: 121505. Reproducción autorizada.

p. 203, Catastro Municipal Ayuntamiento de Tacubaya, sin título, México, 1915, Archivo Histórico del Distrito Federal, Planero Metálico, f. 12, núm. 136.

p. 224, autor no conocido, Demolición del portal de los Mier, ciudad de México, ca. 1929, colección particular.

p. 225, Compañía Mexicana de Aerofoto, Tacubaya D. F, ciudad de México, ca. 1935, Compañía Mexicana de Aerofoto, núm. 515.

p. 227, Compañía Editora de Postales, Banco de México sucursal Tacubaya, ciudad de México, ca. 1935, CNMH/CONACUITA-INAH/635-49. 